\title{
Article \\ Electrochemical Comparison on New (Z)-5-(Azulen-1-Ylmethylene)-2-Thioxo-Thiazolidin-4-Ones
}

\author{
Eleonora-Mihaela Ungureanu ${ }^{1}$, Mariana Popescu (Apostoiu) ${ }^{1}$, Georgiana-Luiza Tatu (Arnold) ${ }^{1}$, Liviu Birzan ${ }^{2}$, \\ Raluca Isopescu ${ }^{1}$, Gabriela Stanciu ${ }^{3}$ and George-Octavian Buica ${ }^{1, *}$ \\ 1 Faculty of Applied Chemistry and Materials Science, University Politehnica of Bucharest \\ 1-7 Gh. Polizu Street, 011061 Bucharest, Romania; mihaela.ungureanu@upb.ro (E.-M.U.); \\ maripope64@yahoo.com (M.P.); aluizaluiza@yahoo.com (G.-L.T.); r_isopescu@chim.upb.ro (R.I.) \\ 2 Institut of Organic Chemistry "C. D. Nenitzescu" of the Romanian Academy, 202B Spl. Independentei, \\ 71141 Bucharest, Romania; lbirzan@cco.ro \\ 3 Department of Chemistry and Chemical Engineering, Ovidius University, 124 Mamaia Blvd., \\ 900527 Constantza, Romania; gstanciu@univ-ovidius.ro \\ * Correspondence: george.buica@upb.ro; Tel.: +40-21-402-3930
}

\section{check for} updates

Citation: Ungureanu, E.-M.; Popescu (Apostoiu), M.; Tatu (Arnold), G.-L.; Birzan, L.; Isopescu, R.; Stanciu, G.; Buica, G.-O. Electrochemical Comparison on New (Z)-5-(Azulen-1-Ylmethylene)-2Thioxo-Thiazolidin-4-Ones. Symmetry 2021, 13, 588. https://doi.org/ $10.3390 /$ sym 13040588

Academic Editor: Edwin

Charles Constable

Received: 10 March 2021

Accepted: 29 March 2021

Published: 2 April 2021

Publisher's Note: MDPI stays neutra with regard to jurisdictional claims in published maps and institutional affiliations.

Copyright: (c) 2021 by the authors. Licensee MDPI, Basel, Switzerland. This article is an open access article distributed under the terms and conditions of the Creative Commons Attribution (CC BY) license (https:// creativecommons.org/licenses/by/ $4.0 /)$.

\begin{abstract}
Three (Z)-5-(azulen-1-ylmethylene)-2-thioxo-thiazolidin-4-ones are electrochemically characterized by cyclic voltammetry, differential pulse voltammetry, and rotating disk electrode voltammetry. The electrochemical investigations revealed that the redox potential is influenced by the number and position of the alkyl groups, and the possible oxidation mechanism is proposed. These compounds, after their immobilization on glassy carbon electrodes during oxidative electropolymerization, were examined as complexing ligands for heavy metal ions from aqueous solutions through adsorptive stripping voltammetry.
\end{abstract}

Keywords: (Z)-5-(azulen-1-ylmethylene)-2-thioxo-thiazolidin-4-ones; electrochemical characterization; modified electrodes; metal detection

\section{Introduction}

Azulene is an isomer of naphthalene, but they are essentially different. While naphthalene has biaxial symmetry, azulene has single symmetry about the $\mathrm{x}$-axis, which gives the azulene system an asymmetric charge distribution. This causes azulene to present important properties, such as a significant dipole moment and remarkable chemical, electronic and optical behavior. As a result, such a system can have many technical applications in optoelectronics [1,2], medicine [3], Li-S batteries [4], supercapacitors [5], photovoltaic cells [6], sensing and imaging [7], etc. The ability of the electrons to move easily from the seven-member cycle to the five-member cycle [8] allows the azulene molecule to act as a donor and acceptor of electrons [9]. For the same reason, it is also possible to use azulenes as building blocks for the development of new molecules [10-12]. Azulene can polymerize via electrochemistry resulting in polymers with high electrical conductivity [13]. If they are properly substituted, they can complex specific targets. Moreover, if they are immobilized on an electrode surface, it could lead to materials that are able to enhance sensitivity and selectivity towards metal ions [14,15].

In line with our previous work $[10-12,14,15]$, the results given in this paper are related to the electrochemical characterization of new azulene compounds and highlight their complexing properties towards metal ions [16]. The studied compounds are derivatives of (Z)-5-(azulen-1-ylmethylene)-2-thioxo-thiazolidin-4-one (L1). Its structure contains the two essential elements of molecular recognition: a complexing part (2-thioxo-thiazolidin-4-one ring) [17] and a polymerizable part-azulene moiety.

The 2-thioxo-thiazolidin-4-one (rhodanine) is a very important heterocyclic compound used to synthesize different compounds because of its biological activity. The applications 
of its antiviral, anticancer, and antimicrobial activity were recently reviewed [18]. It is also known for its complexing properties towards heavy metals [17]. The azulene derivative of rhodanine can be used for accurate metal determination in the same way that the $\mathrm{p}$ dimethylaminophenylidenrhodanine was used to accurately determine $\mathrm{Cu}, \mathrm{Ni}, \mathrm{Fe}$, and Zn [19], or the way in which triarylamine rhodanine derivatives were used as colorimetric sensors to detect $\mathrm{Ag}$ and $\mathrm{Hg}$ ions [20].

Electrochemical polymerization of the ligand on the electrode results in a high density of complexing groups, which allows accumulation of metal ions on its surface [21-24].

The three (Z)-5-(azulen-1-ylmethylene)-2-thioxo-thiazolidin-4-ones (Figure 1) were compared by the curves obtained through electrochemical methods (cyclic voltammetry $(\mathrm{CV})$, differential pulse voltammetry (DPV), and rotating disk electrode (RDE) voltammetry). This comparison allowed the establishment of the main characteristics for their polymerization processes. Then, they were used as ligands for the preparation of complexing modified electrodes. The obtained modified electrodes were compared in terms of heavy metal sensing properties [25].<smiles>[R]c1ccccc2c(/C=C3/C(=O)NC(=S)[SH]3C)ccc1-2</smiles>

Figure 1. Structure of (Z)-5-(azulen-1-ylmethylene)-2-thioxo-thiazolidin-4-ones; R: H (L1); 4,6,8-Me 3 (L2); 3,8-Me $2-5-\mathrm{iPr}(\mathbf{L} 3)$.

\section{Materials and Methods}

The azulene derivatives were synthesized according to the previously published procedure [26]. The electrochemical experiments were performed either in non-aqueous supporting electrolyte $(0.1 \mathrm{M})$ ) (obtained from acetonitrile (Sigma Aldrich, electronic grade 99.999\%) and tetra-n-butylammonium perchlorate (TBAP) (Fluka, puriss, electrochemical grade $>99 \%$ )) or in $0.1 \mathrm{M}$ acetate buffer solution (obtained from sodium acetate (Roth, $99.99 \%$ ) and acetic acid (Fluka, $>99.0 \%$, trace select)). The ionic metal solution was obtained from the corresponding metal salts. Purified water $(18.2 \mathrm{M} \Omega \mathrm{cm})$, was obtained from a Millipore Direct-Q 3UV water purification system and used to prepare the aqueous solutions.

A PGSTAT 12 AUTOLAB potentiostat (Metrohm/Eco Chemie) was used to perform the electrochemical experiments by connecting it to a classical 3-electrode cell. The working electrode was a glassy carbon disk ( $3 \mathrm{~mm}$, from Metrohm), and the counter electrode was a Pt wire. $\mathrm{Ag} / 10 \mathrm{mM} \mathrm{AgNO} 3$ in $0.1 \mathrm{M}$ TBAP, $\mathrm{CH}_{3} \mathrm{CN}$ and $\mathrm{Ag} / \mathrm{AgCl}, 3 \mathrm{M} \mathrm{KCl}$ reference electrodes were used for experiments performed in non-aqueous and aqueous solutions, respectively. For the electrochemical studies performed in the organic solvent, all the potentials were reported from the potential of the ferrocene/ferrocenium redox couple $\left(\mathrm{Fc} / \mathrm{Fc}^{+}\right)$, which was $+0.07 \mathrm{~V}$ in our conditions. Before each measurement, the surface of the working electrode was cleaned with diamond paste $(0.25 \mu \mathrm{m})$ and rinsed with acetonitrile.

The electrochemical experiments performed by CV, DPV, and RDE were recorded for millimolar solutions of L1, 4(Z)-2-thioxo-5-((4,6,8-trimethylazulen-1-yl)methylene)thiazolidin-4one (L2), or (Z)-2-thioxo-5-((3,8-Me2-5-iPr-1-yl)methylene)thiazolidin-4-one (L3) in $0.1 \mathrm{M}$ TBAP, $\mathrm{CH}_{3} \mathrm{CN}$ starting from the stationary potential. $\mathrm{CV}$ was performed at different scan rates between 0.1 and $1.0 \mathrm{~V} \mathrm{~s}^{-1}$. DPV was conducted with a scan rate of $0.01 \mathrm{~V} \mathrm{~s}^{-1}$ with a pulse height of $0.025 \mathrm{~V}$ and a step time of $0.2 \mathrm{~s}$. RDE curves were recorded at $0.01 \mathrm{~V} \mathrm{~s}^{-1}$ for different rotation rates.

The electrochemical behavior of the pattern of (Z)-5-((azulen-1-yl)methylene)-2-thioxothiazolidin-4-one ligand (L1) and (Z)-2-thioxo-5-((4,6,8-trimethylazulen-1-yl)methylene)thiazolidin- 
4-one (L2) has previously been shown $[17,27]$. The redox characteristics of $(\mathrm{Z})$-2-thioxo-5((3,8-Me2-5-iPr-1-yl)methylene)thiazolidin-4-one (L3) were emphasized in a PhD thesis produced by our group [25].

The immobilization of the ligands on the electrode surface was accomplished through controlled potential electrolysis (CPE) from $0.1 \mathrm{mM}$ TBAP, $\mathrm{CH}_{3} \mathrm{CN}$ solutions $(1 \mathrm{mM})$ of $\mathbf{L 1}$, $\mathbf{L} 2$, or $\mathbf{L} 3$. The accumulation and detection of metal ions were performed using a previously described procedure $[14,15]$. Briefly, the accumulation of metal ions was performed by chemical accumulation in an open circuit for $15 \mathrm{~min}$. After careful rinsing with purified water (to remove the unbound ions), the accumulated ions were reduced to metal zerovalent $(-1.2 \mathrm{~V})$ for $120 \mathrm{~s}$, followed by the recording of DPV stripping curves.

In order to remove the influence of the dissolved oxygen, all measurements were performed under an argon atmosphere.

\section{Results and Discussions}

\subsection{Studies by DPV}

DPV overlaid curves for all compounds at same concentration are shown in Figure 2. The oxidation and reduction peaks are further denoted in their appearance order during DPV scans (a1, a2, c1, c2 ... ).

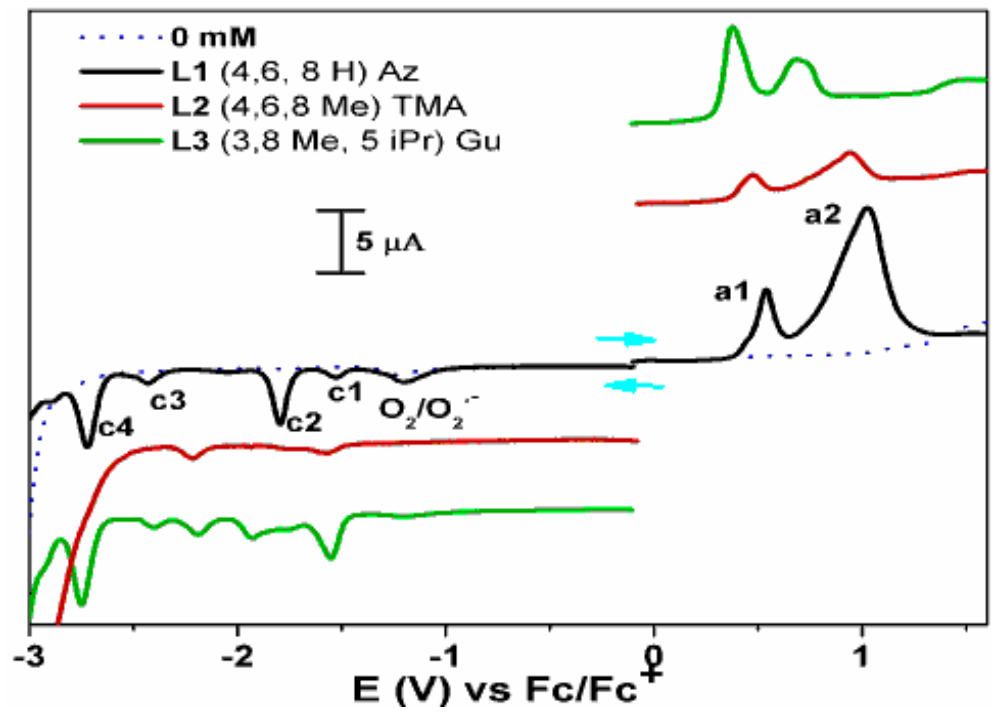

Figure 2. Differential pulse voltammetry (DPV) $\left(0.01 \mathrm{~V} \mathrm{~s}^{-1}\right)$ anodic and cathodic curves for L1, L2, and L3 (at $0.5 \mathrm{mM})$.

From the DPV curves, it can be observed that there are two main peaks for each ligand in the anodic domain. In the cathodic domain, there are different numbers of peaks: two for L2 (c1, c2), three peaks for L3 (c1-c3), and four peaks for L1 (c1-c4). Their potentials and the assessment of the peaks are given in Table 1. The increase in DPV peak currents with concentration can be used to develop an analytical method for the evaluation of concentration for unknown samples.

The $\pi$ system of these compounds is identical, so the number of signals must be similar. The different numbers of observed peaks for each compound can be explained by the fact that the peaks can double by the protonation of ligands. The possible redox processes are illustrated in Scheme 1.

The two main DPV peaks correspond to the electron transfers formulated in Scheme 1 for these compounds. The first anodic step consists of the oxidation of azulene moiety (which is the electron-richest part of this structure), while the first cathodic peak is due to the reduction of the rhodanine cycle (the most electronegative part of the compound). 
Table 1. Potentials (V vs. Fc/Fc+) of the peaks and their assessment.

\begin{tabular}{|c|c|c|c|c|c|c|c|}
\hline \multirow{3}{*}{ Peak } & \multicolumn{2}{|c|}{ L1 [23] } & \multicolumn{2}{|c|}{ L2 [15] } & \multicolumn{2}{|c|}{ L3 } & \multirow{3}{*}{ Assessed Process } \\
\hline & \multicolumn{2}{|c|}{ Method } & \multicolumn{2}{|c|}{ Method } & \multicolumn{2}{|c|}{ Method } & \\
\hline & DPV & $\mathrm{CV}$ & DPV & $\mathrm{CV}$ & DPV & $\mathrm{CV}$ & \\
\hline $\mathrm{O}_{2} / \mathrm{O}_{2} \cdot-$ & -1.202 & $-1.316(\mathrm{i})$ * & - & - & - & - & $\begin{array}{l}\text { Oxygen reduction } \\
\text { Low peak current process }\end{array}$ \\
\hline $\mathrm{c} 1$ & -1.528 & - & -1.541 & - & -1.543 & $-1.610(\mathrm{i}) *$ & $\begin{array}{l}\text { (negligible) due to reduction of the } \\
\text { protonated ligand }\end{array}$ \\
\hline c2 & -1.801 & $-1.842(\mathrm{q})$ * & -2.216 & $-2.112(r)$ * & - & $-1.991(q) *$ & $\begin{array}{l}\text { Reduction of } \mathrm{C}=\mathrm{C} \text { bond } \\
\text { Low peak current process }\end{array}$ \\
\hline c3 & -2.431 & $-2.482(q) *$ & - & - & -2.191 & $-2.430(\mathrm{q}) *$ & $\begin{array}{l}\text { (negligible) due to the reduction of } \\
\text { a fragment (probably as a result of } \\
\text { the decomposition of the azulene }\end{array}$ \\
\hline $\mathrm{c} 4$ & -2.721 & $-2.794(\mathrm{q}) *$ & - & - & -2.748 & $-2.831(q) *$ & Reduction of the C-S bond \\
\hline a1 & 0.541 & $0.578(\mathrm{i})$ * & 0.473 & $0.493(\mathrm{i}) *$ & 0.373 & $0.421(\mathrm{i}) *$ & Radical cation formation \\
\hline a2 & 1.021 & $1.143(\mathrm{i})$ * & 0.942 & $0.847(\mathrm{i}) *$ & 0.673 & $0.721(\mathrm{i}) *$ & Oligomer oxidation \\
\hline a3 & - & - & - & $1.571(\mathrm{i})$ * & - & $1.490(\mathrm{i})$ * & $0-$ \\
\hline $\mathrm{a} 4$ & - & - & - & - & - & $1.785(\mathrm{i}) *$ & - \\
\hline
\end{tabular}

${ }^{*} \mathrm{q}$-quasi-reversible process; i-irreversible process.
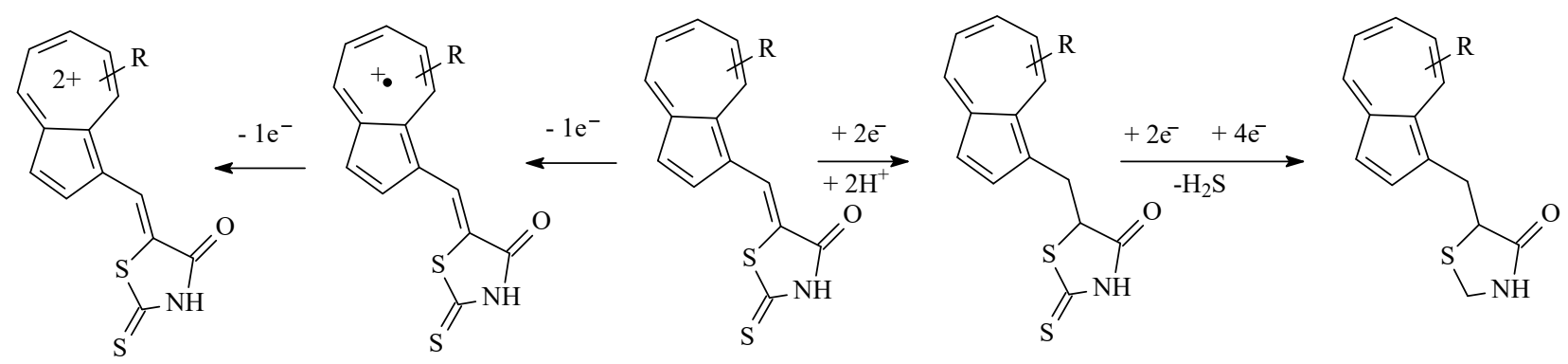

Scheme 1. Electrochemical oxidation and reduction processes for (Z)-5-((azulen-1-1)methylene)-2-thioxo-thiazolidin-4-ones.

The small peaks in the cathodic region could be explained by the existence of a small concentration of the protonated compounds, which are more easily reduced due to their positive charge, so each peak has a pair at lower potentials.

At higher anodic and cathodic potentials, the electrochemical processes become nonselective and the whole molecule is destroyed.

As expected, the alkyl groups induce a positive inductive effect and increase the electron densities of the molecules. Therefore, the alkyl-substituted compounds are easier to be oxidized and harder to be reduced than the pattern compound. However, the steric effect of these groups makes the reductions more difficult to anticipate, and the reduction potentials can sometimes even be reversed by this effect.

The azulene (Az) system is more stable when it is symmetrically substituted, but it becomes very reactive by unsymmetrical substitution (the symmetry of the aromatic system is disrupted by the difference in the alkyl group's electronic influence). Therefore, the compounds containing three symmetrically substituted groups (like 4,6,8-three methyl azulene (TMA)) have higher activation energies than those unsymmetrically substituted, like guaiazulene $(\mathrm{Gu})$. Therefore, it is expected that guaiazulene will react faster than TMA, despite its higher volume.

The experimental results show that the redox potential is influenced by the number and position of the alkyl groups, as assumed previously (Figure S1 of the Supplementary Materials). The Gu-azulene fragment $\left(3,8-\mathrm{Me}_{2}-5-\mathrm{iPr}-\mathrm{Az}\right)$ from $\mathbf{L} 3$ is more easily oxidized than the TMA-azulene fragment $\left(4,6,8-\mathrm{Me}_{3}-\mathrm{Az}\right)$ from $\mathbf{L} 2$, which is more easily oxidized than the azulene fragment (Az) from L1. These compounds present a first anodic DPV peak at $0.373 \mathrm{~V}, 0.493 \mathrm{~V}$, and $0.541 \mathrm{~V}$, respectively. In reduction, the potential order is reversed, but the differentiation is less obvious because the reductions occur specifically in 
the heterocyclic part (the first cathodic peaks of these compounds in DPV have the values of $-1.529 \mathrm{~V},-1.541 \mathrm{~V}$, and $-1.543 \mathrm{~V}$ for L1, L2, and L3, respectively). These curves also show an important variation in the peak current values for the same concentration of the ligands (Figure 2). The differences observed for the peak a1 current values can be attributed to errors during the experiment due to the low solubility of these compounds. However, the values for the height of a1 and c1 peaks agree with their expected solubility, which varies in the order $\mathbf{L} 3>\mathbf{L} 1>\mathbf{L} 2$.

\subsection{Studies by CV}

From the CV curves, it can be observed that in the oxidation domains for compounds L2 and L3, only two peaks are significant (a1 and a2). The peaks situated at more positive potentials (a3 and a4) belong to the supporting electrolyte (drawn with dotted line). In the reduction domain, each compound presents a different number of peaks: compound L1 has three reduction peaks (c2-c4); compound L2 has one reduction peak (c2); compound L3 has three reduction peaks (c1, c3, c4) (Figure S2 of the Supplementary Materials). The potentials of the CV peaks are given in Table 1. Like in the case of DPV curves, it is observed that the $\mathrm{CV}$ redox peak potentials are influenced by the number and position of the alkyl groups (Table 1). The L1, L2, and L3 compounds present their first anodic CV peaks at $0.578 \mathrm{~V}$, $0.493 \mathrm{~V}$, and $0.421 \mathrm{~V}$, respectively (Figure 3). These potentials are well correlated with the peak potentials obtained by DPV. The reduction potentials are more difficult to establish in CV because the presence of oxygen traces leads to unwanted overlaps. The increase in $\mathrm{CV}$ peak currents with concentration can be used to develop an analytical method for the evaluation of concentration for unknown samples, as in the case of DPV.

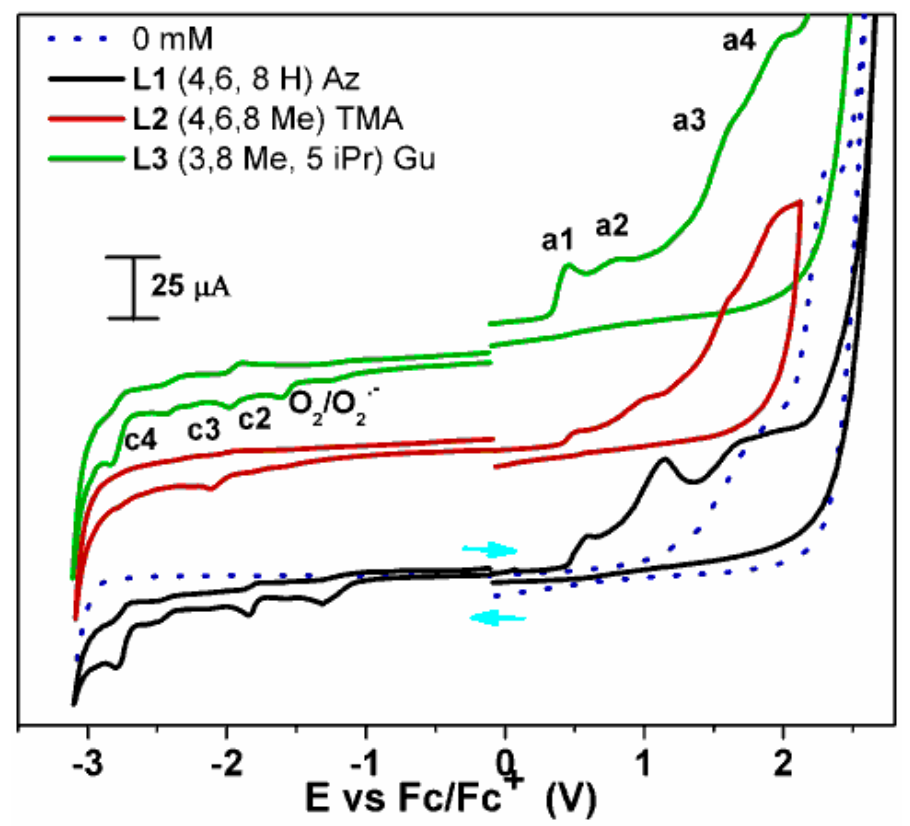

Figure 3. Cyclic voltammetry (CV) $\left(0.1 \mathrm{Vs}^{-1}\right)$ anodic and cathodic curves for L1, L2, L3 (at $\left.0.5 \mathrm{mM}\right)$.

Figure 4 shows the anodic and cathodic voltammograms for L3 on different scan domains, and Table 1 presents the potentials ( $\mathrm{V}$ vs. $\mathrm{Fc} / \mathrm{Fc}^{+}$) of the peaks and their assessment. It can be seen in the anodic domain that all the processes show an irreversible behavior, while in the cathodic one, they are quasi-reversible or irreversible, like in the case of the other two compounds (Figure S3 of the Supplementary Materials).

Voltammograms were also recorded at different scan rates, as seen in Figure 5, for the anodic and cathodic scans of compound L3. In the inset of Figure 5, the linear dependences of the (a1) and (c1) processes on the square root of the scan rate are shown. The slopes vary in the following order: L3 > L1 > L2 (Table 2). Their different slopes can be explained by 
their solubility, which varies in the same order. As the solubility of these compounds is quite low, studies are usually performed in oversaturated solutions from which the ligand sometimes precipitates; this phenomenon is difficult to control because the solution is intensely colored.

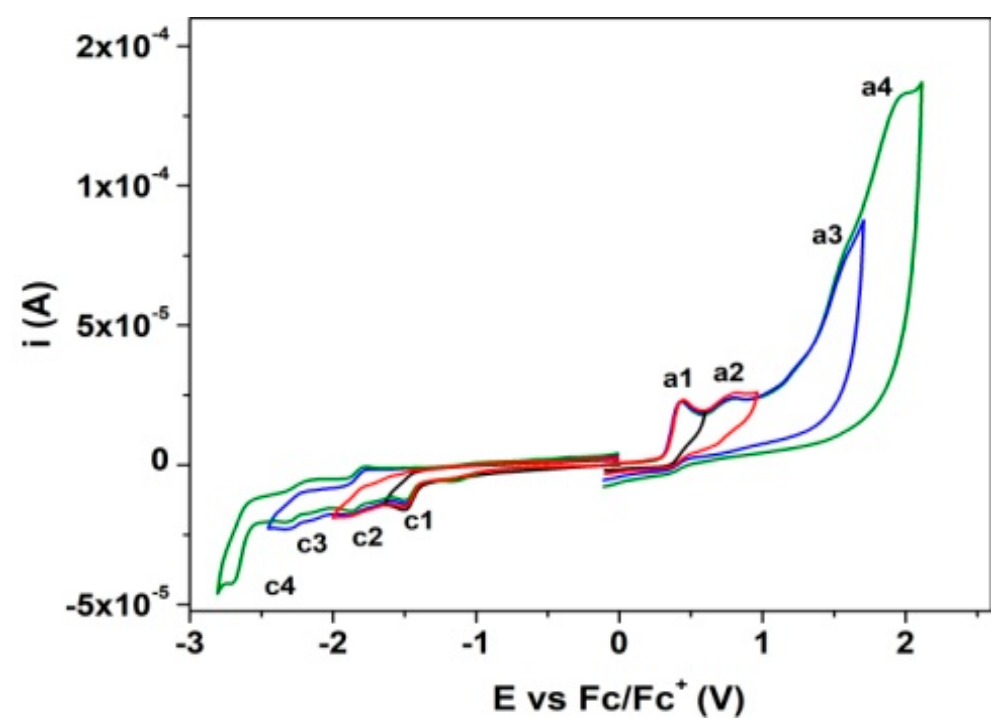

Figure 4. Anodic and cathodic CV $\left(0.1 \mathrm{~V} \mathrm{~s}^{-1}\right)$ curves for $\mathbf{L 3}(0.5 \mathrm{mM}$ in $0.1 \mathrm{M}$ tetra-n-butylammonium perchlorate (TBAP), $\mathrm{CH}_{3} \mathrm{CN}$ ) on different scan domains.

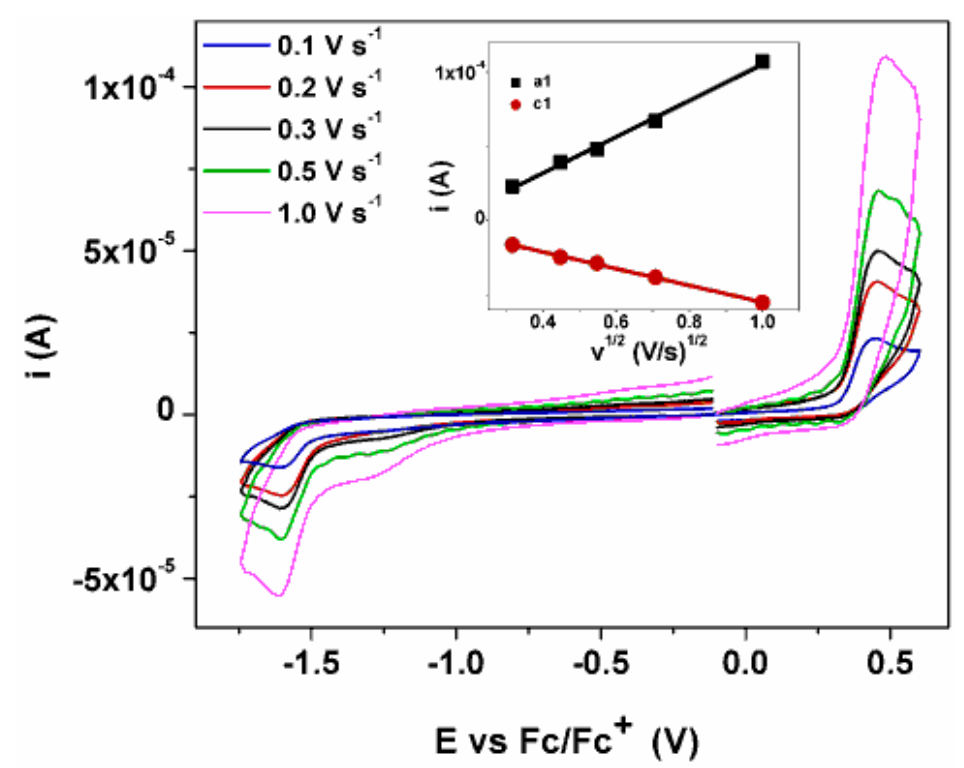

Figure 5. Anodic and cathodic voltammograms at different scan rates for L3 (0.5 mM); inset: linear dependences of the (a1) and (c1) processes on the square root of the scan rate.

Using the Randles-Sevcik equation for an irreversible process [28], the diffusion coefficients were calculated for one electron transfer (Table 3). The diffusion coefficient (D) value varies in the same order as it is the solubility of the compounds $\left(D_{\mathbf{L} 3}>D_{\mathbf{L 1}}>\mathrm{D}_{\mathbf{L 2}}\right)$. This result is probably due to their different structures, but it is also connected to their actual concentration in solution. There is a lack of precision in the evaluation of the actual concentration values of the working solutions due to the precipitation of compounds from the oversaturated solutions. Consequently, the results for D are influenced (the concentration is diminished due to uncontrolled precipitation), especially for the less soluble compounds L1 and L2. Therefore, D values for L1 and L2 are much lower than for L3. The linear 
dependence of the peak current as a function of the square root of the scan rate (Figure 5, inset) also highlights a diffusion-controlled process $[29,30]$.

Table 2. Equations obtained for the linear dependences of first anodic (a1) and cathodic (c1) peak currents (in A) on the square root of the scan rate (in $\mathrm{V} \mathrm{s}^{-1}$ ) for $\mathbf{L 1}-\mathbf{L} 3$.

\begin{tabular}{|c|c|c|}
\hline & ipa1 vs. $v^{1 / 2}$ & ipc1 vs. $v^{1 / 2}$ \\
\hline L1 & $\begin{array}{c}\mathrm{ip}_{\mathrm{a} 1}=-3.80 \times 10^{-6}+44.67 \times 10^{-6} \times \mathrm{v}^{1 / 2} \\
\mathrm{R}^{2}=0.998\end{array}$ & Not recorded \\
\hline L2 & $\begin{array}{c}\mathrm{ip}_{\mathrm{a} 1}=-6.58 \times 10^{-6}+40.2 \times 10^{-6} \times \mathrm{v}^{1 / 2} \\
\mathrm{R}^{2}=0.935\end{array}$ & $\begin{array}{c}\mathrm{ip}_{\mathrm{c} 1}=-1.25 \times 10^{-6}-24.6 \times 10^{-6} \times \mathrm{v}^{1 / 2} \\
\mathrm{R}^{2}=0.971\end{array}$ \\
\hline $\mathbf{L 3}$ & $\begin{array}{c}\mathrm{ip}_{\mathrm{a} 1}=-16.66 \times 10^{-6}+122.07 \times 10^{-6} \times \mathrm{v}^{1 / 2} \\
\mathrm{R}^{2}=0.995\end{array}$ & $\begin{array}{c}\mathrm{ip}_{\mathrm{c} 1}=1.58 \times 10^{-6}-56.44 \times 10^{-6} \times \mathrm{v}^{1 / 2} \\
\mathrm{R}^{2}=0.998\end{array}$ \\
\hline
\end{tabular}

Table 3. Estimated diffusion coefficients of the ligands (for a concentration of $0.5 \mathrm{mM}$ in each compound in $0.1 \mathrm{M}$ TBAP, $\left.\mathrm{CH}_{3} \mathrm{CN}\right)$.

\begin{tabular}{cccc}
\hline Compound & L1 & L2 & L3 \\
\hline $10^{5} \times \mathrm{D}\left(\mathrm{cm}^{2} \mathrm{~s}^{-1}\right)$ & 2.2 & $1.8^{*}$ & 16.5 \\
\hline *Previously calculated value [15]. & &
\end{tabular}

* Previously calculated value [15].

\subsection{Studies by $R D E$}

Figure 6 shows the RDE curves at different rotation rates for these compounds in $0.1 \mathrm{M}$ TBAP, $\mathrm{CH}_{3} \mathrm{CN}$. The processes are denoted with respect to the peak notation from the DPV curves. The studied compounds have regular behavior in the cathodic domain, where two main waves are seen for all compounds. For the investigated ligands, the behavior in the anodic domain is different in comparison with that in the cathodic domain. In the anodic domain, the currents drop suddenly after the a2 peak for all compounds. A similar drop has been seen in other azulene compounds [23,31]. This drop is connected to the oxidation of the ligands with the formation of insulating layers that cover the electrode. Isosbestic points appear only for $\mathbf{L} 2$ (at about $0.8 \mathrm{~V}$ ) and for $\mathbf{L} \mathbf{3}($ at $0.7 \mathrm{~V}$ ). When the rotation rate increases from $500 \mathrm{rpm}$ to $1000 \mathrm{rpm}$, for the pair of peaks a1 and a2, the increase in current for L3 is bigger than in the case of the other two ligands. This involves either weak polymerization in the case of L3 (as it will be shown further in the study of L3 polymerization) or a lower solubility for $\mathbf{L} 2$ than $\mathbf{L} 3$ (as discussed before, $\mathbf{L} 3>\mathbf{L 1}>\mathbf{L} 2$ ).

The behavior in RDE at different concentrations is similar for all compounds (the current increases with concentration). Figure 7A gives as examples the curves for L1 at $1000 \mathrm{rpm}$ [26] and $\mathbf{L 3}$ at $500 \mathrm{rpm}$. The RDE waves from the oxidation domain change to peaks, as was shown for other azulenes [23,31]. This behavior is attributed to the formation of a compact film on the electrode surface. The film formation noticed by RDE occurs at the potential of the RDE peak a2: $0.686 \mathrm{~V}$ for L3, $0.785 \mathrm{~V}$ for L2 (Figure 7B), and $0.927 \mathrm{~V}$ for L1 (Figure 7C). These values agree with the potentials of the DPV peaks previously obtained. The values of the currents are consistent with the solubility of the compounds (the solubility of these compounds is different and quite low). Consequently, the electrochemical studies are performed usually in oversaturated solutions from which the ligand sometimes precipitates. This phenomenon is difficult to control because the solution is intensely colored. Better control of the concentration of the compounds L1, L2, and $\mathbf{L 3}$ could be obtained in more dilute solutions (where the precipitation can be avoided), but the results are not clearly seen as peaks in these conditions for CV, DPV, or RDE experiments.

In the reduction domain, mainly two waves are seen for all compounds. 

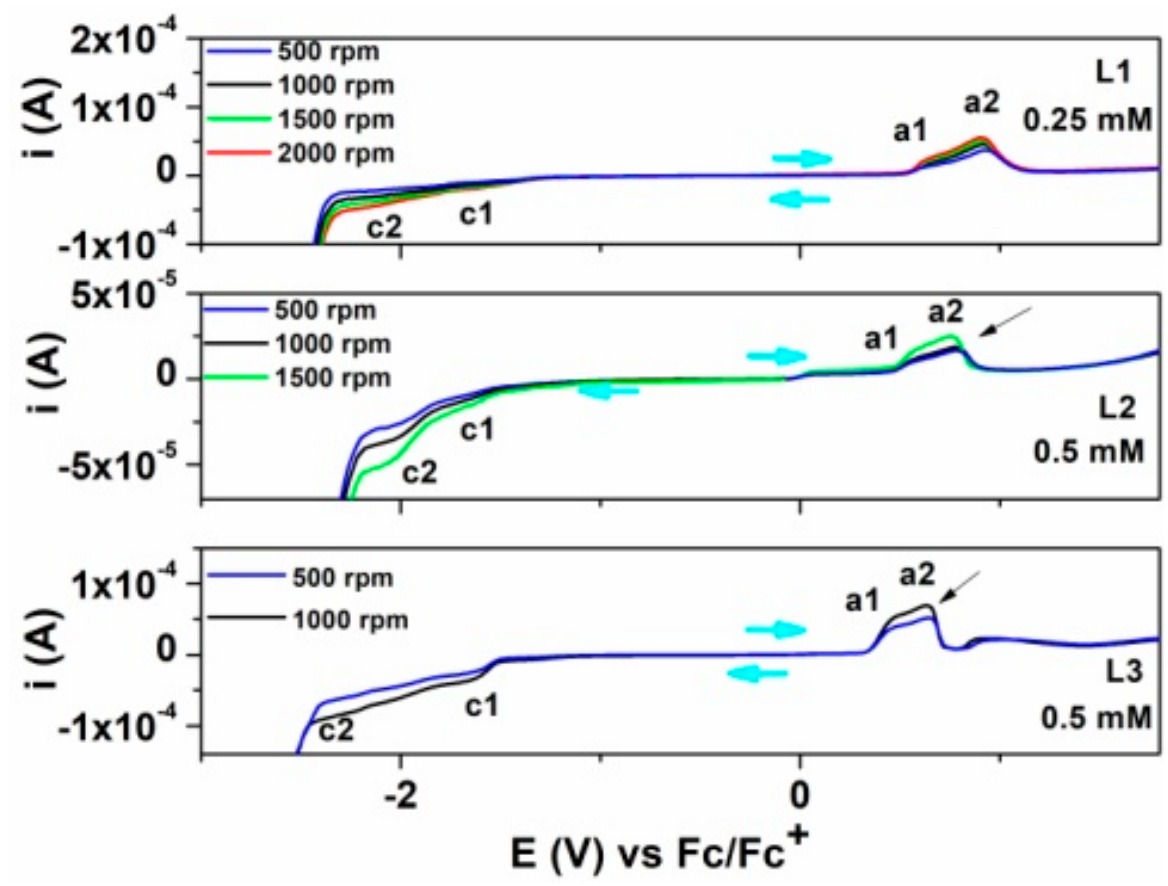

Figure 6. Rotating disk electrode (RDE) $\left(0.01 \mathrm{~V} \mathrm{~s}^{-1}\right)$ curves at different rotation rates for compounds L1, L2, and L3.
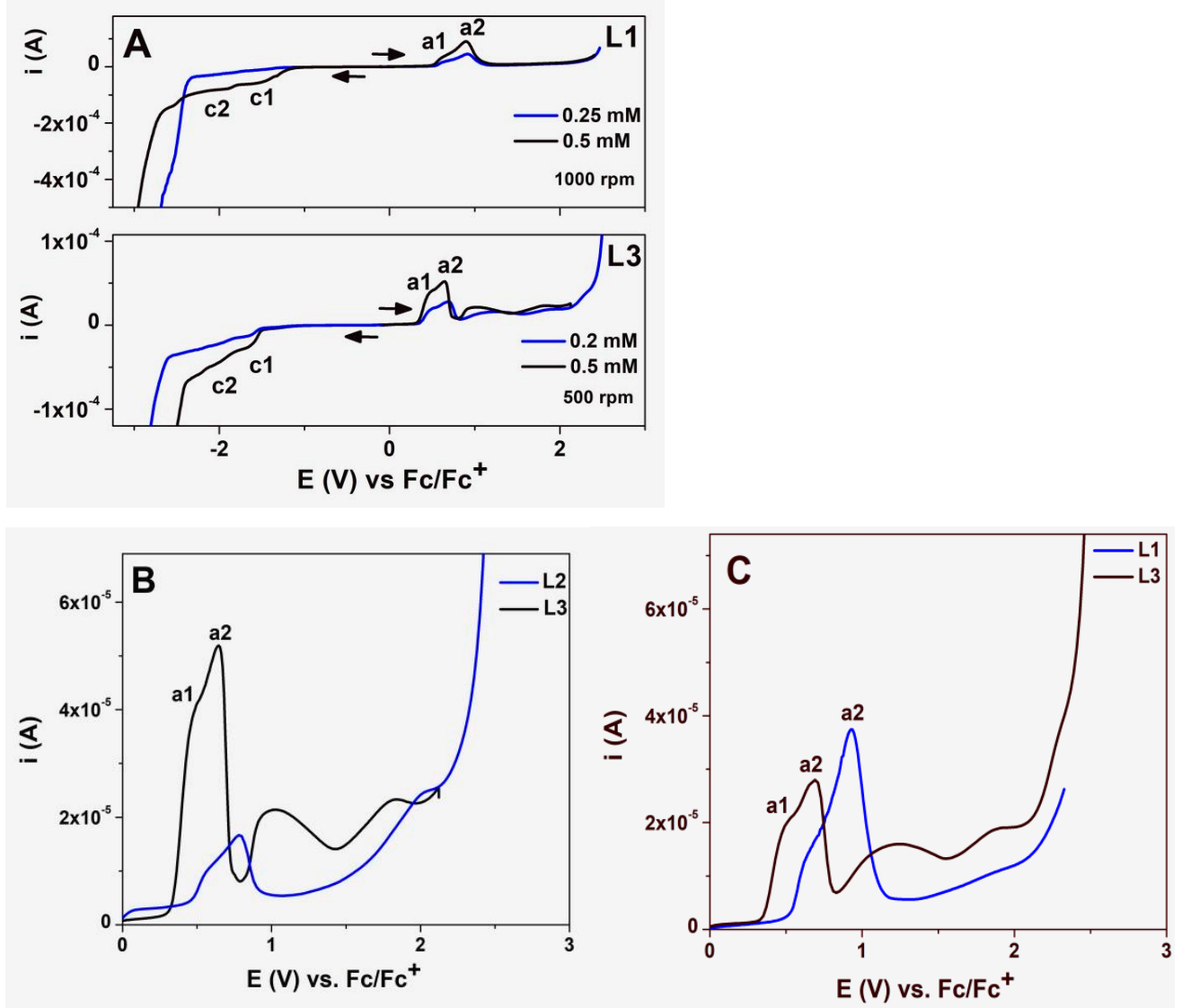

Figure 7. (A). RDE $\left(0.01 \mathrm{~V} \mathrm{~s}^{-1}\right)$ anodic and cathodic curves at different concentrations for $\mathbf{L} 1$ and L3; (B). RDE (0.01 $\left.\mathrm{V} \mathrm{s}^{-1}\right)$ anodic curves at $500 \mathrm{rpm}$ and $0.5 \mathrm{mM}$ for L2 and L3; (C). RDE $\left(0.01 \mathrm{~V} \mathrm{~s}^{-1}\right)$ anodic curves at $500 \mathrm{rpm}$ for L1 and L3 (0.2 mM). 


\subsection{Modified Electrodes}

Chemically modified electrodes were obtained either by potentiodynamic oxidation during 20 successive cycles or by CPE at different potentials and different amounts of electrical charges. The obtained electrodes were transferred in $1 \mathrm{mM}$ ferrocene solution, and the signal was recorded. The voltammograms recorded with the modified electrodes were compared with those obtained on the bare electrode.

The goal was a modified electrode that yielded positive results with L1 [27], both by $\mathrm{CPE}$ and by successive cycling. The ferrocene signal recorded on the modified electrode was diminished when compared with the signal obtained from the bare electrode. The electrode surface was covered by an insulating layer of polyL1, as was seen in electrochemical impedance spectroscopy and scanning electron microscopy studies [32]. The topography of atomic force microscopy (AFM) images exhibited the presence of columnar shape features. AFM results also revealed a dependence of surface roughness on the electropolymerization parameters (potential/charge) [33]. Similar behavior was observed for L2 after the transfer of the modified electrodes into ferrocene probe solution [17], showing the coverage of the electrode with polyL2 films. The behavior of L3 was different. The attempts to obtain polyL3 films either by 20 successive cycles (Figure 8 ) or by CPE led to very small changes in the ferrocene signal.

Different electropolymerization charges $(0.2-0.8 \mathrm{mC})$ and potentials $(0.59-2.12 \mathrm{~V})$ in $\mathrm{CPE}$ did not lead to significant ferrocene signal changes compared to the bare electrode (Figure S4 of the Supplementary Materials). This behavior could be explained by a weak $\pi$ polymerization in the case of $\mathbf{L} 3$, since 3,8-Me $-\mathrm{Me}_{2}-5$-iPr substituents are bulkier than 4,6,8- $\mathrm{Me}_{3}$ of $\mathbf{L} 2$ and $\mathbf{H}$ of $\mathbf{L} 1$. Other types of polymerization are not possible because these ligands have the most reactive position (3) blocked by substitution.

\subsection{Metal Binding Properties}

The ability of modified electrodes with L1, L2, and $\mathbf{L} 3$ to coordinate and detect metal ions from aqueous probes was achieved through chemical accumulation in an open circuit, followed by anodic stripping [14]. Figure 9 shows the anodic stripping curves obtained with modified electrodes after a $15 \mathrm{~min}$ accumulation time in a solution that contains heavy metal ions ( $\mathrm{Cd}(\mathrm{II}), \mathrm{Pb}(\mathrm{II}), \mathrm{Cu}(\mathrm{II})$, and $\mathrm{Hg}(\mathrm{II}))$, each in a $10^{-6} \mathrm{M}$ concentration.

Not all ligands can complex the studied ions. For polyL1 and polyL2, lead stripping currents are higher than those for cadmium, copper, and mercury. The curves in Figure 9 indicate a preferential recognition for lead out of all ligands, followed by cadmium and a specific detection of copper by polyL2. In the case of polyL3, a specific detection of cadmium and lead was noticed. For polyL1 and polyL3, no response for $\mathrm{Cu}$ and $\mathrm{Hg}$ was found. This shows a higher affinity of the ligands towards $\mathrm{Pb}(\mathrm{II})$ and $\mathrm{Cd}(\mathrm{II})$ ions. This selectivity can be explained by the fact that this type of compound can give substitution reactions in the free position three of the azulene fragment with the formation of organomercuric compounds. These compounds have different electrochemical properties, and the $\mathrm{Hg}$ peaks are considerably diminished [34].

The electrode modified with $\mathbf{L} 2$ detected all of the metal ions in the accumulation solutions but with different intensities varying in the following order: $\mathrm{Pb}>\mathrm{Cu}>\mathrm{Cd}>>\mathrm{Hg}$.

The analytical properties of these modified electrodes towards metal ion detection are under consideration. 

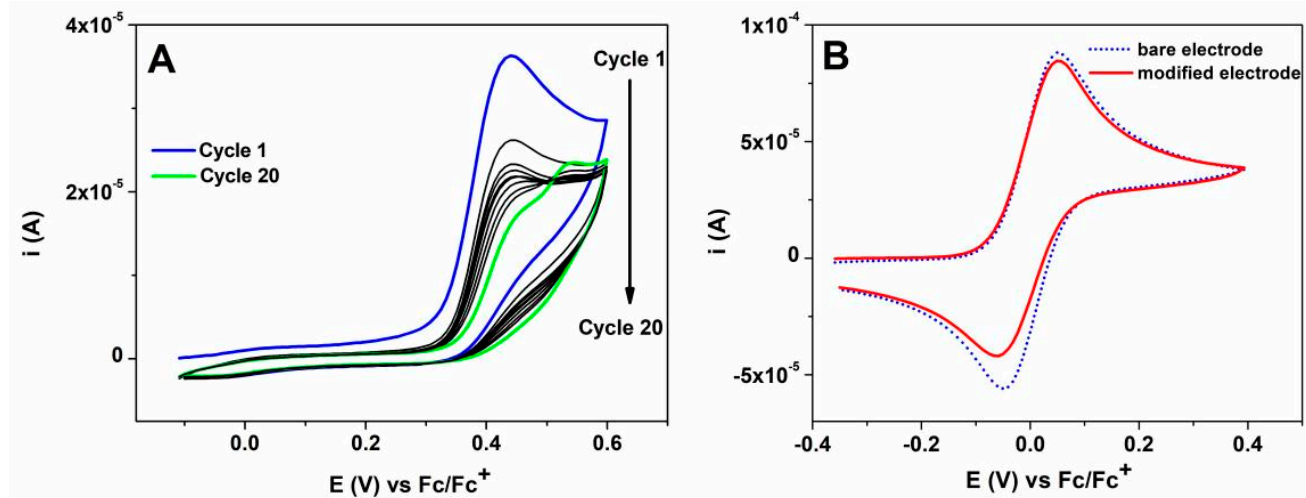

Figure 8. (A) Successive voltammograms $\left(0.1 \mathrm{~V} \mathrm{~s}^{-1}\right)$ in $0.5 \mathrm{mM}$ solution of $\mathbf{L} 3$ (20 successive cycles) and $(\mathbf{B})$ the corresponding $\mathrm{CV}\left(0.1 \mathrm{~V} \mathrm{~s}^{-1}\right)$ curve recorded on the electrode obtained in Figure $8 \mathrm{~A}$ in ferrocene solution $(1 \mathrm{mM})$ in comparison with the bare electrode.

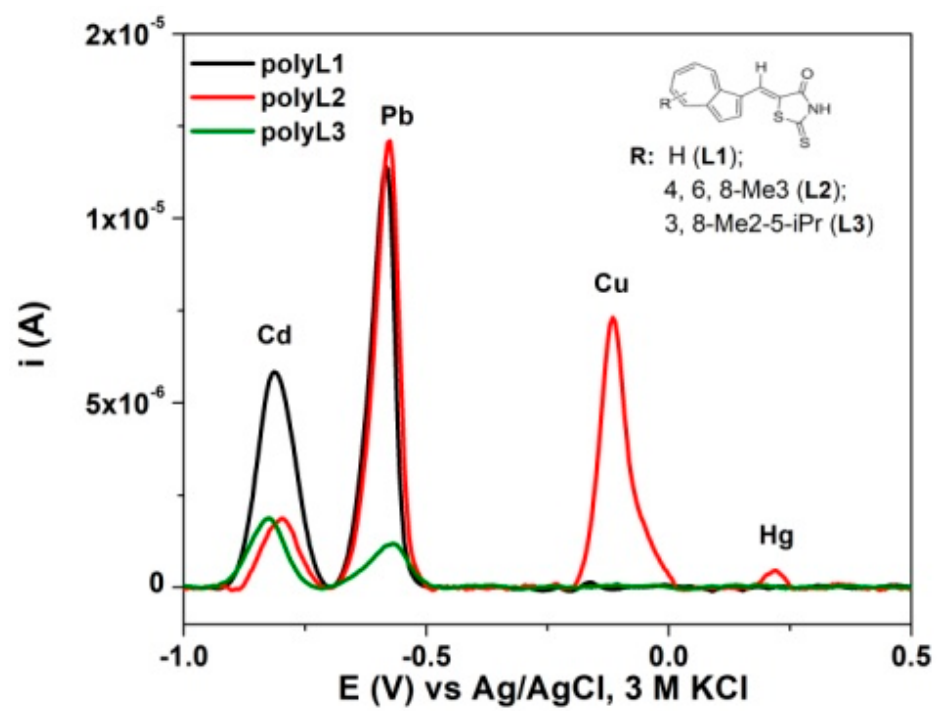

Figure 9. DPV curves in acetate buffer $(\mathrm{pH}=5.5)$ of modified electrodes obtained by controlled potential electrolysis (CPE) with different ligands (L1, L2, L3) after 15 min of accumulation in a solution containing a concentration of $10^{-6} \mathrm{M}$ from all of the following cations: $\mathrm{Cd}(\mathrm{II}), \mathrm{Pb}(\mathrm{II}), \mathrm{Cu}(\mathrm{II})$, and $\mathrm{Hg}(\mathrm{II})$.

\section{Conclusions}

The electrochemical characterization of several (Z)-5-(azulen-1-ylmethylene)-2-thioxothiazolidin-4-ones was performed using CV, DPV, and RDE. Modified electrodes were obtained by successive cycling of the potential or by controlled potential electrolysis at different potentials or amounts of electric charges. The responses of the modified electrodes for heavy metal ion recognition were evaluated. The best results in the recognition of heavy metal ions were obtained for $\mathrm{Pb}(\mathrm{II})$ with polyL1.

The stripping curves indicate a preferential recognition for lead by all ligands, followed by cadmium, and a specific detection of copper by polyL2. In the case of polyL3, a specific detection of cadmium and lead was observed. The lack of response from polyL1 and poly $\mathrm{L} 3$ towards $\mathrm{Cu}$ and $\mathrm{Hg}$ indicates their potential use to build sensors based on modified electrodes for $\mathrm{Pb}$ (II) and $\mathrm{Cd}$ (II) ions. The detection intensities in relation to different heavy metals using these ligands vary as follows: polyL1 > polyL2 $\sim$ polyL3 (for Cd), polyL2 $>$ polyL1 > poly $\mathbf{L} 3$ (for $\mathrm{Pb}$ ), while polyL2 is selective for $\mathrm{Cu}$. The investigated azulene derivatives of rhodanine can be used for very accurate metal determination of $\mathrm{Pb}, \mathrm{Cd}$, and $\mathrm{Cu}$. The sensing properties towards heavy metal ions are in progress. 
Supplementary Materials: The following are available online at https:/ / www.mdpi.com/article/ 10.3390/sym13040588/s1: Figure S1: DPV (10 $\left.\mathrm{mV} \mathrm{s}^{-1}\right)$ anodic and cathodic curves at different concentrations for L1, L2, L3; Figure S2: CV $\left(0.1 \mathrm{~V} \mathrm{~s}^{-1}\right)$ anodic and cathodic curves at different concentrations for L1, L2, L3 in $0.1 \mathrm{M}$ TBAP, $\mathrm{CH}_{3} \mathrm{CN}$; Figure S3: Anodic and cathodic $\mathrm{CV}\left(0.1 \mathrm{~V} \mathrm{~s}^{-1}\right)$ curves for all compounds $\left(0.5 \mathrm{mM}\right.$ in $0.1 \mathrm{M}$ TBAP, $\left.\mathrm{CH}_{3} \mathrm{CN}\right)$ on different scan domains; insets: details of cathodic domains; Figure S4: $\mathrm{CV}\left(0.1 \mathrm{~V} \mathrm{~s}^{-1}\right)$ curves $\left(1 \mathrm{mM}\right.$, in $0.1 \mathrm{M}$ TBAP, $\left.\mathrm{CH}_{3} \mathrm{CN}\right)$ obtained after the transfer of the modified polyL3 electrodes in ferrocene solution for modified electrodes prepared by CPE: A—at different electropolymerization charges $(0.2 \mathrm{mC} ; 0.4 \mathrm{mC} ; 0.6 \mathrm{mC} ; 0.8 \mathrm{mC})$ at $0.95 \mathrm{~V}$; and B-at different electropolymerization potentials $(0.59 \mathrm{~V} ; 0.95 \mathrm{~V} ; 1.71 \mathrm{~V} ; 2.12 \mathrm{~V})$ at $0.8 \mathrm{mC}$ in comparison with the bare electrode (dotted line).

Author Contributions: E.-M.U. and G.-O.B. designed the study and methodology, supervised, and wrote the main manuscript text. L.B. performed the organic synthesis, and G.S. and R.I. oversaw the characterization of the ligands. M.P. and G.-L.T. performed the electrochemical experiments and wrote the corresponding part of the manuscript. All authors have read and agreed to the published version of the manuscript.

Funding: This research was funded by Romanian National Authority for Scientific Research, UEFISCDI, under grant PN-III-P2-2.1-PED-2019-0730, contract no. 293PED/2020.

Institutional Review Board Statement: Not applicable.

Informed Consent Statement: Not applicable.

Acknowledgments: The authors gratefully acknowledge the financial support of the Romanian National Authority for Scientific Research, UEFISCDI, under grant PN-III-P2-2.1-PED-2019-0730, contract no. 293PED/2020.

Conflicts of Interest: The authors declare no conflict of interest.

\section{References}

1. Dong, J.-X.; Zhang, H.-L. Azulene-based organic functional molecules for optoelectronics. Rev. Chin. Chem. Lett. 2016, 27, 1097-1104. [CrossRef]

2. Xin, H.; Gao, X. Application of Azulene in Constructing Organic Optoelectronic Materials: New Tricks for an Old Dog. Chem. Plus. Chem. 2017, 82, 945-956. [CrossRef] [PubMed]

3. Bakun, P.; Czarczynska-Goslinska, B.; Goslinski, T.; Lijewski, S. In vitro and in vivo biological activities of azulene derivatives with potential applications in medicine. Med. Chem. Res. 2021, 30, 834-846. [CrossRef]

4. Chen, Z.; Droste, J.; Zhai, G.; Zhu, J.; Yang, J.; Hansen, M.R.; Zhuang, X. Sulfur-anchored azulene as a cathode material for Li-S batteries. Chem.Commun. 2019, 55, 9047-9050. [CrossRef]

5. Suominen, M.; Lehtimäki, S.; Yewale, R.; Damlin, P.; Tuukkanen, S.; Kvarnström, C. Electropolymerized polyazulene as active material in flexible supercapacitors. J. Power Sources 2017, 356, 181-190. [CrossRef]

6. Yang, L.; Zhu, Y.; Liu, J.; Chen, Y.; Wu, J.; Pang, Z.; Lu, Z.; Zhao, S.; Huang, Y. Marked effects of azulenyl vs. naphthyl groups on donor-pi-acceptor-pi-donor small molecules for organic photovoltaic cells. Dyes Pigment. 2021, 187, 109079. [CrossRef]

7. Murfin, L.C.; Lewis, S.E. Azulene-A bright core for sensing and imaging. Molecules 2021, 26, 353. [CrossRef] [PubMed]

8. Dutta, S.; Lakshmi, S.; Pati, S.K. Comparative study of electron conduction in azulene and naphthalene. Bull. Mater. Sci. 2008, 31, 353-358. [CrossRef]

9. Ungureanu, E.-M.; Amarandei, C.A.; Caval, D.I.; Buica, G.-O.; Razus, A.C.; Birzan, L. Electrochemical synthesis of azo azulene films. J. Optoelectron. Adv. Mater. 2010, 12, 1805-1810.

10. Buica, G.-O.; Lazar, I.-G.; Birzan, L.; Lete, C.; Prodana, M.; Enachescu, M.; Tecuceanu, V.; Stoian, A.B.; Ungureanu, E.-M. Azuleneethylenediaminetetraacetic acid: A versatile molecule for colorimetric and electrochemical sensors for metal ions. Electrochim. Acta 2018, 263, 382-390. [CrossRef]

11. Buica, G.-O.; Birzan, L.; Tecuceanu, V.; Razus, A.C.; Arnold, G.-L.; Ungureanu, E.-M. Modified Electrodes Based on Poly[(2E)2-(Azulen-1-ylmethylidene)hydrazinecarbothioamide] for Heavy Metal Ions Complexation. Electroanalysis 2017, $29,93-102$. [CrossRef]

12. Amarandei, C.-A.; Buica, G.-O.; Inel, G.A.; Birzan, L.; Ungureanu, E.-M. Study of the complexation of diethyl 2-[(E)-3-azulen-1ylprop-2-enylidene]propanedioate with lanthanide cations. Acta Chim. Slov. 2014, 61, 894-899.

13. Bargon, J.; Mohmand, S.; Waltman, R.J. Polyazulene, A Member of a New Class of Polymers. Mol. Cryst. Liq. Cryst. 1983, 93, 279-291. [CrossRef]

14. Buica, G.-O.; Ivanov, A.A.; Lazar, I.-G.; Tatu (Arnold), G.-L.; Omocea, C.; Birzan, L.; Ungureanu, E.-M.J. Colorimetric and voltammetricsensing of mercury ions using 2,2'-(ethane-1,2-diylbis((2-(azulen-2-ylamino)-2-oxoethyl)azanediyl))diacetic acid. J. Electroanal. Chem. 2019, 849, 113351. [CrossRef] 
15. Buica, G.-O.; Ungureanu, E.-M.; Birzan, L.; Razus, A.C.; Mandoc, L.-R. Voltammetric sensing of lead and cadmium using poly(4-azulen-1-yl-2,6-bis(2-thienyl)pyridine) complexing films. J. Electroanal. Chem. 2013, 693, 67-72. [CrossRef]

16. Birzan, L.; Cristea, M.; Draghici, C.C.; Tecuceanu, V.; Maganu, M.; Hanganu, A.; Arnold, G.-L.; Ungureanu, E.-M.; Razus, A.C. 1-vinylazulenes-Potential host molecules in ligands for metal ions detectors. Tetrahedron 2016, 72, 2316-2326. [CrossRef]

17. Arnold, G.-L.; Lazar, I.G.; Buica, G.-O.; Ungureanu, E.-M.; Birzan, L. New Azulene Modified Electrodes for Heavy Metal Ions Recongnition. Bulg. Chem. Commun. 2017, 49, 205-210.

18. Mousavi, S.M.; Zarei, M.; Hashemi, S.A.; Babapoor, A.; Amani, A.M. A conceptual review of rhodanine: Current applications of antiviral drugs, anticancer and antimicrobial activities. Artif. Cells Nanomed. Biotechnol. 2019, 47, 1132-1148. [CrossRef]

19. Kshirsagar, V.; Gandhem, S.; Gautam, M.D. Electrochemical studies on p-dimethylaminobenzylidine rhodanine and its application as amperometric reagent. Rasāyan J. Chem. 2010, 3, 772-776.

20. Thamaraiselvi, P.; Duraipandy, N.; Kiran, M.S.; Easwaramoorthi, S. Triarylamine rhodanine derivatives as red emissive sensor for discriminative detection of $\mathrm{Ag}^{+}$and $\mathrm{Hg}^{2+}$ ions in buffer-free aqueous solutions. ACS Sustain. Chem. Eng. 2019, 7, 9865-9874. [CrossRef]

21. Wang, F.; Lai, Y.H.; Han, M.Y. Stimuli-Responsive Conjugated Copolymers Having Electro-Active Azulene and Bithiophene Units in the Polymer Skeleton: Effect of Protonation and p-Doping on Conducting Properties. Macromolecules 2004, 37, 3222-3230. [CrossRef]

22. Lash, T.D.; Colby, D.A.; Graham, S.R.; Ferrence, G.M.; Szczpura, L.F. Organometallic chemistry of azuliporphyrins: Synthesis, spectroscopy, electrochemistry and structural characterization of nickel(II), palladium(II) and platinum(II) complexes of azuliporphyrins. Inorg. Chem. 2003, 42, 7326-7338. [CrossRef] [PubMed]

23. Ungureanu, E.-M.; Razus, A.C.; Birzan, L.; Cretu, M.-S.; Buica, G.-O. Electrochemistry of Functionalized Azo Azulenes. Electrochim. Acta 2008, 53, 7089-7099. [CrossRef]

24. Wakabayashi, S.; Uchida, M.; Tanaka, R.; Habata, Y.; Shimizu, M. Synthesis of Azulene Derivatives That Have an Azathiacrown Ether Moiety and Their Selective Color Reaction Towards Silver Ions. Asian J. Org. Chem. 2013, 2, 786-791. [CrossRef]

25. Arnold, G.-L. Sensors Based on Azulene Modified Electrodes for Testing Metals in Waters. Ph.D. Thesis, University Politehnica of Bucharest, Bucharest, Romania, 2017.

26. Birzan, L.; Cristea, M.; Draghici, C.C.; Tecuceanu, V.; Maganu, M.; Hanganu, A.; Razus, A.C.; Buica, G.O.; Ungureanu, E.M. Vinylazulenes chromophores: Synthesis and characterization. Dyes Pigment. 2016, 131, 246-255. [CrossRef]

27. Diacu, E.; Buica, G.-O.; Chilibon, I.; Birzan, L.; Arnold, G.-L.; Ungureanu, E.-M. Chemically Modified Electrodes Based on 5-(Azulen-1-yl)methylene)-2-thioxothiazolidin-4-one. J. Solut. Chem. 2016, 45, 1588-1597. [CrossRef]

28. García-Miranda Ferrari, A.; Foster, C.W.; Kelly, P.J.; Brownson, D.A.C.; Banks, C.E. Determination of the electrochemical area of screen-printed electrochemical sensing platforms. Biosensors 2018, 8, 53. [CrossRef]

29. Balram, D.; Lian, K.Y.; Sebastian, N.; Rasana, N. Ultrasensitive detection of cytotoxic food preservative tert-butylhydroquinone using 3D cupric oxide nanoflowers embedded functionalized carbon nanotubes. J. Hazard. Mater. 2021, 406, 124792. [CrossRef]

30. Jampasa, S.; Siangproh, W.; Duangmal, K.; Chailapakul, O. Electrochemically reduced graphene oxide-modified screen-printed carbon electrodes for a simple and highly sensitive electrochemical detection of synthetic colorants in beverages. Talanta 2016, 160, 113-124. [CrossRef] [PubMed]

31. Lazar, I.G.; Diacu, E.; Arnold, G.-L.; Ungureanu, E.-M.; Buica, G.-O.; Birzan, L. Synthesis and characterization of poly(azulenethiophene vinyl pyrylium) salt. Bulg. Chem. Commun. 2017, 49, 227-232.

32. Pop, M.D.; Anicai, L.; Cristea, M.; Ungureanu, E.-M.; Enachescu, M. Impedance studies on chemically modified electrodes based on 5-[(azulen-1-yl) methylene]-2-thioxothiazolidin-4-one. U.P.B. Sci. Bull. Series B 2017, 79, 3-12.

33. Pop, M.D.; Brincoveanu, O.; Cristea, M.; Buica, G.O.; Enachescu, M. AFM and SEM characterization of chemically modified electrodes based on 5-[(azulen-1-yl) methylene]-2-thioxothiazolidin-4-one. Rev. Chim. 2017, 68, 2799-2803. [CrossRef]

34. Nefedov, V.A.; Obshch, K.Z. Substitution reactions of copper salts. Chem. Abs. 1969, 71, 50159. 